\title{
Potential effects of cryogenic extraction biases on inferences drawn from xylem water deuterium isotope ratios: case studies using stable isotopes to infer plant water sources
}

\section{Scott T. Allen ${ }^{1} \&$ James W. Kirchner ${ }^{2,3}$}

${ }^{1}$ Dept. of Natural Resources and Environmental Science, University of Nevada, Reno, USA

${ }^{2}$ Dept. of Environmental Systems Science, ETH Zürich, Zürich, Switzerland

${ }^{3}$ Swiss Federal Research Institute WSL, Birmensdorf, Switzerland

\begin{abstract}
Recent studies have demonstrated that plant and soilwater extraction techniques can introduce biases and uncertainties in stable isotope analyses. Here we show how recently documented $\delta^{2} \mathrm{H}$ biases resulting from cryogenic vacuum distillation of water from xylem tissues may have influenced the conclusions of five previous studies, including ours, that have used $\delta^{2} \mathrm{H}$ to infer plant water sources. Cryogenic extraction biases that reduce xylem water $\delta^{2} \mathrm{H}$ will also introduce an artifactual evaporation signal in dual-isotope $\left(\delta^{2} \mathrm{H}\right.$ vs. $\left.\delta^{18} \mathrm{O}\right)$ analyses. Calculations that estimate the composition of the source precipitation of xylem waters by compensating for their apparent evaporation will amplify the bias in $\delta^{2} \mathrm{H}$, and also introduce new biases in the $\delta^{18} \mathrm{O}$ of the inferred pre-evaporation source precipitation. Cryogenic extraction biases may substantially alter plant water source attributions if the spread in $\delta^{2} \mathrm{H}$ among the potential end members is relatively narrow. By contrast, if the spread in $\delta^{2} \mathrm{H}$ among the potential end members is relatively wide, the impact of cryogenic extraction biases will be less pronounced, and thus suggestions that these biases universally invalidate inferences drawn from plant water $\delta^{2} \mathrm{H}$ are unwarranted. Nonetheless, until reliable correction factors for cryogenic extraction biases become available, their potential impact should be considered in studies using xylem water isotopes.
\end{abstract}

\section{Introduction}

Recent studies have suggested that commonly used methods for extracting water from soils and plant tissues may bias determinations of those waters' isotopic $\delta^{18} \mathrm{O}$ and $\delta^{2} \mathrm{H}$ values (Barbeta et al., 2020a; Chen et al., 2020; Fischer et al., 2019; Gaj and McDonnell, 2019; Li et al., 2021; Newberry et al., 2017; Orlowski et al., 2018b, 2018a). Chen et al. (2020) have recently demonstrated that $\delta^{2} \mathrm{H}$ in xylem water extracted by cryogenic vacuum distillation averaged $\sim 8.1 \%$ lower than both the plants' source water and their transpired vapor, with the extraction bias varying by species from -5.2 to $-10.9 \%$ o $\delta^{2} \mathrm{H}$. Regardless of whether this bias is introduced by cryogenic extraction itself (Chen et al., 2020), root uptake and within-plant transport (Barbeta et al., 2020a; Ellsworth and Williams, 2007; Poca et al., 2019), or sample handling routines (Fischer et al., 
2019), evidence suggests that $\delta^{2} \mathrm{H}$ determined from cryogenically extracted plant xylem water can differ substantially from the $\delta^{2} \mathrm{H}$ of plant water uptake.

Such insights are important because they suggest how the resulting data should be interpreted and they enable progress towards developing correction factors to compensate for extraction biases. Chen et al. (2020), however, also state that such extraction artifacts are in "violation" of a "prerequisite" for using xylem water samples to infer source water isotope ratios. The implication of that statement is that $\delta^{2} \mathrm{H}$ in xylem water cannot be used to identify plant water sources. Our view is less absolute. All analytical work entails uncertainties and biases; the key question is whether they are large or small compared to the environmental signals that we seek to detect, measure, or interpret. Uncertainties and biases that are small compared to the environmental signals of interest will have correspondingly small effects on the measured signals and the inferences that are drawn from them. Conversely, uncertainties and biases that are not small compared to the signals of interest can fundamentally alter the inferences that are drawn from environmental measurements. Biases are particularly problematic in this regard because they cannot be averaged out by more extensive sampling; on the other hand, if they are sufficiently predictable, one can potentially compensate for their effects.

As a simple mathematical illustration of these basic principles, we consider how the biases described by Chen et al.

45 (2020) could affect a simple mixing model that partitions a xylem water sample X (with an isotopic del value of $\delta \mathrm{X}$ ) among two end-members, shallow and deep soil waters $\mathrm{S}$ and $\mathrm{D}$ (with del values of $\delta \mathrm{S}$ and $\delta \mathrm{D}$, respectively). The conventional endmember mixing equations yield the result that the fraction of $\mathrm{X}$ attributable to end-member $\mathrm{S}$ is

$$
f_{\mathrm{S}}=\frac{\delta \mathrm{X}-\delta \mathrm{D}}{\delta \mathrm{S}-\delta \mathrm{D}}
$$

and its standard error, as calculated by Gaussian error propagation, is (see, for example, the supplement to Kirchner and Allen,

50 2020),

$$
\mathrm{SE}\left(f_{\mathrm{S}}\right)=\sqrt{\left(\frac{1}{\delta \mathrm{S}-\delta \mathrm{D}} \mathrm{SE}(\delta \mathrm{X})\right)^{2}+\left(\frac{\delta \mathrm{D}-\delta \mathrm{X}}{(\delta \mathrm{S}-\delta \mathrm{D})^{2}} \mathrm{SE}(\delta \mathrm{S})\right)^{2}+\left(\frac{\delta \mathrm{S}-\delta \mathrm{X}}{(\delta \mathrm{S}-\delta \mathrm{D})^{2}} \mathrm{SE}(\delta \mathrm{D})\right)^{2}},
$$

or, equivalently,

$$
\mathrm{SE}\left(f_{\mathrm{S}}\right)=\frac{\sqrt{\mathrm{SE}(\delta \mathrm{X})^{2}+\left(f_{\mathrm{S}} \mathrm{SE}(\delta \mathrm{S})\right)^{2}+\left(\left(1-f_{\mathrm{S}}\right) \mathrm{SE}(\delta \mathrm{D})\right)^{2}}}{|\delta \mathrm{S}-\delta \mathrm{D}|},
$$

55 where $\mathrm{SE}(\delta \mathrm{X}), \mathrm{SE}(\delta \mathrm{S})$, and $\mathrm{SE}(\delta \mathrm{D})$ represent the standard errors of the isotope values of the xylem water and the two endmembers. Now, what if the xylem water measurement does not yield the unmeasured value $\delta \mathrm{X}$ but instead a biased value $\delta \mathrm{X}^{*}=\delta \mathrm{X}+\delta \mathrm{B}$ (where $\delta \mathrm{B}$ represents the bias)? In this case, end-member mixing will not yield the unbiased estimate $f_{\mathrm{S}}$, but instead the biased estimate $f_{\mathrm{S}}^{*}$,

$$
f_{\mathrm{S}}^{*}=\frac{\delta \mathrm{X}^{*}-\delta \mathrm{D}}{\delta \mathrm{S}-\delta \mathrm{D}}=\frac{\delta \mathrm{X}+\delta \mathrm{B}-\delta \mathrm{D}}{\delta \mathrm{S}-\delta \mathrm{D}}
$$


60 and thus the distortion in the source fraction $f_{\mathrm{S}}$ is

$$
f_{\mathrm{S}}^{*}-f_{\mathrm{S}}=\frac{\delta \mathrm{B}}{\delta \mathrm{S}-\delta \mathrm{D}} .
$$

Equation (4) shows that if the bias $\delta \mathrm{B}$ is a small fraction of the isotopic difference $\delta \mathrm{S}-\delta \mathrm{D}$ between the end members, it will introduce a correspondingly small distortion in the source fraction $f_{\mathrm{S}}$. Conversely if the bias $\delta \mathrm{B}$ is a not a small fraction of the isotopic difference $\delta \mathrm{S}-\delta \mathrm{D}$, the distortion in $f_{\mathrm{S}}$ could be substantial. In principle, if the bias can be estimated, it can be subtracted to derive an estimate $\hat{f}_{\mathrm{S}}$ that is closer to the true source fraction $f_{\mathrm{S}}$ than the biased estimate $f_{\mathrm{S}}^{*}$,

$$
\hat{f}_{\mathrm{S}}=\frac{\delta \mathrm{X}^{*}-\delta \mathrm{B}-\delta \mathrm{D}}{\delta \mathrm{S}-\delta \mathrm{D}}=f_{\mathrm{S}}^{*}-\frac{\delta \mathrm{B}}{\delta \mathrm{S}-\delta \mathrm{D}}
$$

Equation (5) is mathematically equivalent to Eq. (1), but Eq. (1) cannot be employed in practice because if the xylem water extractions introduce bias, one will never measure the unbiased value $\delta \mathrm{X}$ but instead only the biased value $\delta \mathrm{X}^{*}$. This

70 distinction matters because, although one can subtract the estimated bias $\delta \mathrm{B}$, that estimate itself will be uncertain and thus will introduce additional uncertainty into the bias-corrected source fraction $\hat{f}_{\mathrm{S}}$, as follows:

$$
\begin{gathered}
\mathrm{SE}\left(\hat{f}_{\mathrm{S}}\right)=\frac{\sqrt{\mathrm{SE}\left(\delta \mathrm{X}^{*}\right)^{2}+\mathrm{SE}(\delta \mathrm{B})^{2}+\left(f_{\mathrm{S}} \mathrm{SE}(\delta \mathrm{S})\right)^{2}+\left(\left(1-f_{\mathrm{S}}\right) \mathrm{SE}(\delta \mathrm{D})\right)^{2}}}{|\delta \mathrm{S}-\delta \mathrm{D}|} \\
=\sqrt{\mathrm{SE}\left(f_{\mathrm{S}}^{*}\right)^{2}+\left(\frac{\mathrm{SE}(\delta \mathrm{B})}{\delta \mathrm{S}-\delta \mathrm{D}}\right)^{2}} .
\end{gathered}
$$

Readers should note that the major uncertainty in $\delta \mathrm{B}$ may not arise from uncertainty in the isotope measurements used to estimate it, but instead from uncertainty in whether the experiments (including the specific plants) that were used to estimate

$75 \delta \mathrm{B}$ are relevant to the particular situations where those estimates are employed (i.e., in subsequent studies that will use different individual plants and perform the extractions in different labs). Readers should also note that $\mathrm{SE}(\delta \mathrm{B})$ should be added (in quadrature) to $\operatorname{SE}\left(\delta \mathrm{X}^{*}\right)$ for other types of analyses as well, such as, for example, t-tests used to evaluate whether xylem water and groundwater isotope ratios are significantly different.

In the following section, we assess how the cryogenic extraction biases reported by Chen et al. (2020) could

80 potentially alter the conclusions of five studies, including ours, that have used $\delta^{2} \mathrm{H}$ measurements in xylem water to identify plant water sources. The studies were selected because their analyses and inferences exhibit a range of sensitivity to potential biases, not because they are representative of the total body of literature. We increase the plant xylem water $\delta^{2} \mathrm{H}$ values reported in these previous studies by $+8.1 \%$, to correct for the average $-8.1 \%$ bias between cryogenically extracted xylem water and source water measured by Chen et al. (2020). We use simplified versions of the original papers' data and analyses

85 since we lack the data needed to fully replicate the original calculations, and thus our results should be taken as suggestive but not definitive. For one of the reviewed studies (Allen et al., 2019b), we have the raw data, and thus can show a more in-depth analysis of how cryogenic extraction $\delta^{2} \mathrm{H}$ biases can become amplified in dual-isotope applications. We do not address the 
potential consequences of cryogenic extraction biases in soilwater samples, because the current literature lacks a sufficiently clear consensus on the magnitude, or even the direction, of such potential biases in soilwater extractions. Although further research is also needed to determine how cryogenic extraction biases in xylem water vary among species and among laboratories, we use $-8.1 \%$ for purposes of illustration. We emphasize that the actual bias for any given species and any given laboratory's extraction procedures could differ substantially, in either direction, from this illustrative number.

\section{Evaluation of bias-correction effects in previous studies}

Case A: Water sources of riparian trees (Dawson and Ehleringer, 1991)

Dawson and Ehleringer (1991) compared $\delta^{2} \mathrm{H}$ values of cryogenically extracted xylem water from several categories of trees with soilwater, groundwater, and nearby streamwater. The xylem water $\delta^{2} \mathrm{H}$ of large streamside trees was $-133.3 \%$, light enough relative to the nearly static streamwater $\delta^{2} \mathrm{H}$ of $-121.4 \%$ to suggest that these trees used groundwater instead, based on the similarity between their xylem water $\delta^{2} \mathrm{H}$ and groundwater from nearby wells (-132.3\%). However, the groundwater and streamwater are separated by only $11 \% \delta^{2} \mathrm{H}$, so correcting the xylem water $\delta^{2} \mathrm{H}$ for a possible cryogenic extraction bias of $-8.1 \%$ would raise it to $-125.2 \%$, placing it closer to the streamwater than the groundwater (Fig. 1A). By contrast, the xylem water $\delta^{2} \mathrm{H}$ of younger, non-streamside trees $\left(-89.6 \pm 4.3 \% \delta^{2} \mathrm{H}\right)$ was sufficiently different from both the groundwater and streamwater that neither would be a plausible water source, whether or not the xylem water samples were affected by cryogenic extraction artifacts. In this case, soilwaters (ranging from approximately -30 to $-120 \% \delta^{2} \mathrm{H}$ ) are a more plausible water source, and cover a sufficiently wide isotopic range that this inference would be mostly unaffected by a -8.1 $\%$ bias in xylem water $\delta^{2} \mathrm{H}$ (Fig. 1A).

Case B: Root water uptake of plants inferred from deuterium in a floodplain site, a cold desert site, and a mountain front site (Thorburn and Ehleringer, 1995)

In a floodplain site, $\delta^{2} \mathrm{H}$ averaged $-27 \%$ in groundwater, $-28 \%$ in deep soilwater, and $-15 \%$ in shallow soilwater.

110 The similar $\delta^{2} \mathrm{H}$ values in average groundwater and deep soilwater effectively preclude using them as distinct end members. Xylem water was reported as $-25 \% \delta^{2} \mathrm{H}$, implying that the primary sources were groundwater and deep soilwater, but correcting for a presumed $-8.1 \%$ bias would raise this xylem water value to $-17 \%$, implying that nearly all water uptake was from shallow soils, not deep soils or groundwater. Because the potential cryogenic extraction bias is not small compared to the isotopic separation between the end members, it could substantially affect the inferred water source attribution.

In the cold desert site, $\delta^{2} \mathrm{H}$ averaged $-91 \%$ in groundwater, $-82 \%$ in deep soilwater, and -64 \%o in shallow soilwater. These potential sources were more isotopically distinct than those in the floodplain site. The reported xylem $\delta^{2} \mathrm{H}$ of $-73 \%$ was intermediate to the shallow and deep soilwater values, roughly matching soils of 0.2 to $0.4 \mathrm{~m}$ deep (see Fig. 5 in Thorburn and Ehleringer, 1995). If the xylem $\delta^{2} \mathrm{H}$ value were shifted by $+8.1 \%$ to $-65 \%$, to compensate for presumed cryogenic extraction biases, it would still overlap with the observed soil $\delta^{2} \mathrm{H}$ values at roughly $0.2 \mathrm{~m}$ depth. However, in a two-source 
mixing model context, the uncorrected xylem water $\delta^{2} \mathrm{H}$ value of $-73 \%$ would imply a roughly even mixture of shallow and deep soilwater, whereas the corrected value would imply that nearly all plant water uptake was sourced from the shallowest soil layers (Fig. 1B).

In Thorburn and Ehleringer's mountain-front site (the same study area described in Case A), the xylem water $\delta^{2} \mathrm{H}$ $(-130 \%$ ) was nearly identical to groundwater $(-131 \%)$ and distinctly different from soilwater (-100\%o), implying that groundwater was the dominant plant water source. If we correct for a presumed cryogenic extraction bias of $-8.1 \%$, the xylem water $\delta^{2} \mathrm{H}$ value becomes $-122 \%$, implying a potential $30 \%$ contribution from soilwater. Nonetheless, the isotopic difference between the soilwater and groundwater end members is large enough that groundwater would be identified as the dominant plant water source, whether or not the xylem water $\delta^{2} \mathrm{H}$ were corrected for cryogenic extraction artifacts.

Case C: Depth of soilwater used in a semi-arid forest across seasons (Kerhoulas et al., 2013)

Kerhoulas et al. (2013) quantified how water sources of Ponderosa pine trees varied across seasons; here we analyze the reported mean values from the dry season of Spring 2009 and the monsoon season of Summer 2010. In the dry season of Spring 2009, soilwater $\delta^{2} \mathrm{H}$ exhibited a strong gradient, from $-37 \%$ at $0-2 \mathrm{~cm}$ depth to -81 and $-91 \%$ at depths of $19-21 \mathrm{~cm}$ and 39-41 cm, respectively. The average xylem water $\delta^{2} \mathrm{H}$ of $-92 \%$ suggested that the trees were using $\sim 40 \mathrm{~cm}$ deep soilwater;

135 if it were shifted by $+8.1 \%$ to compensate for presumed cryogenic extraction biases, the xylem water $\delta^{2} \mathrm{H}$ would become -84 $\%$, implying water uptake from depths closer to $20 \mathrm{~cm}$ (e.g., Fig. 1C). In the 2010 monsoon season, $\delta^{2} \mathrm{H}$ was $-84,-79$, and -95 $\%$ for soilwaters from depths of 0-2 cm, 19-21 cm, and 39-41 cm, respectively, exhibiting a weaker gradient than was found during the dry season. Shifting the reported xylem $\delta^{2} \mathrm{H}$ of $-95 \%$ by $+8.1 \%$ to $-87 \%$ would result in xylem $\delta^{2} \mathrm{H}$ better matching the $\delta^{2} \mathrm{H}$ of the shallowest soilwater rather than the deepest, or, alternatively, matching soilwater from a depth of

140 roughly $30 \mathrm{~cm}$. Because the highest soilwater $\delta^{2} \mathrm{H}$ was observed at an intermediate depth, the depth of plant water uptake cannot be unambiguously determined without additional information. This example illustrates how source attribution can sometimes be easier during dry periods, during which evaporative fractionation can develop strong $\delta^{2} \mathrm{H}$ soil-water gradients (Muñoz-Villers et al., 2018), and more difficult during rainy periods, when these gradients are partially erased by infiltrating precipitation (Sprenger et al., 2016).

Case D: Depth of soil-water uptake by tropical forest trees (Goldsmith et al., 2012)

Goldsmith et al (2012) showed that xylem water $\delta^{2} \mathrm{H}$ values in six tree species were consistent with the use of shallow soilwaters in a seasonally dry Mexican tropical forest. Here we reanalyze xylem water values and matching soilwater profiles for four of the six species, including one that was reported as using deeper sources than the others. Soilwaters from six 150 sampling depths yielded a gradient of mostly decreasing $\delta^{2} \mathrm{H}$, with values ranging from -12 to $-35 \%$ at $5 \mathrm{~cm},-23$ to $-28 \%$ at $15 \mathrm{~cm},-29$ to $-39 \%$ at $30 \mathrm{~cm},-40$ to $-50 \%$ at $50 \mathrm{~cm},-49$ to $-75 \%$ at $70 \mathrm{~cm}$, and -61 to $-79 \%$ at $100 \mathrm{~cm}$. Xylem water $\delta^{2} \mathrm{H}$ values in $Q$. lanceifolia, C. macrophyla, and M. glaberrima varied between - $31 \%$ and $-28 \%$, consistent with soilwaters from depths of roughly $5-30 \mathrm{~cm}$. If these xylem water values were shifted by $+8.1 \%$ to correct for presumed cryogenic extraction 
biases, they would still be consistent with source waters from a similar range of depths. In this case, correcting for the presumed extraction bias would not imply greater use of the shallowest soilwater, because $\delta^{2} \mathrm{H}$ was often highest at roughly $15 \mathrm{~cm}$ depth (see Fig. 3 in Goldsmith et al 2012). If extraction biases differ by species, however, the high-to-low ranking in xylem $\delta^{2} \mathrm{H}$ across these three species may change because they are so close in value. The xylem water $\delta^{2} \mathrm{H}$ of A. latifolia was distinctly lower (-48\%o), coinciding with soilwater $\delta^{2} \mathrm{H}$ from $50 \mathrm{~cm}$ deep; with a $+8.1 \%$ shift, it would still overlap with soilwaters at $50 \mathrm{~cm}$ depths (Fig. 1D). The originally reported findings are therefore generally robust against cryogenic extraction bias, due to the large soilwater gradient $\left(50 \% \delta^{2} \mathrm{H}\right)$ and the relative coarseness of the inferences (e.g., xylem water was qualitatively matched with different depths of soilwaters, rather than being quantitatively divided into fractional uptake from multiple soil layers as in other studies).

Case E: Use of summer versus winter precipitation across sites and species (Allen et al., 2019b).

Allen et al. (2019b) analyzed xylem water from three tree species as a mixture of typical summer and winter precipitation across 182 Swiss forest sites. These seasonal end-members differed by $60 \%$ in $\delta^{2} \mathrm{H}$, averaging $-43 \%$ and -103 $\%$ in summer and winter, respectively; seasonal variations in precipitation $\delta^{2} \mathrm{H}$ are generally large, especially at cold, highelevation, or continental interior locations (Allen et al., 2019a). Average xylem water $\delta^{2} \mathrm{H}$ values of the three measured species were roughly intermediate to those potential sources; on average, beech (-84\%) and oak (-80\%) xylem were closer to winter precipitation than spruce xylem $(-75 \%)$ was. Increasing these values by $+8.1 \%$ to compensate for presumed cryogenic extraction biases would place oak and beech values intermediate between the two sources and shift spruce values towards summer precipitation (Fig. 1E). Compared to the $60 \%$ difference between the seasonal end members, an adjustment of +8.1 $\%$ is relatively small.

However, Allen et al.'s (2019b) analysis also sought to infer the original composition of the source precipitation in dual-isotope space, compensating for the effects of evaporative fractionation. This made their results more vulnerable to cryogenic extraction biases, as described in the next section.

\section{Tracking $\delta^{2} \mathrm{H}$ biases through dual-isotope $\left(\delta^{2} \mathrm{H}\right.$ and $\left.\delta^{18} \mathrm{O}\right)$ applications}

Many water isotope studies measure both $\delta^{2} \mathrm{H}$ and $\delta^{18} \mathrm{O}$. Where measurements for both isotopes are available, $\delta^{2} \mathrm{H}$ has often been preferred because its environmental variability is typically $\sim 8$ times larger than that of $\delta^{18} \mathrm{O}$ but its analytical error is typically only $\sim 3-7$ times larger; thus $\delta^{2} \mathrm{H}$ 's analytical error, relative to its environmental variability, is usually somewhat smaller than $\delta^{18} \mathrm{O}$ 's (see supplemental information to Wassenaar et al., 2018). However, cryogenic extraction biases appear to be much smaller for $\delta^{18} \mathrm{O}$ than for $\delta^{2} \mathrm{H}$ in xylem water (Chen et al., 2020), potentially making $\delta^{18} \mathrm{O}$ a more reliable tracer for plant-water studies. Ultimately, a more robust approach would be to use both isotopes independently, accounting for their respective biases and uncertainties. Each can thus provide a consistency check for the other; if the $\delta^{2} \mathrm{H}$ and $\delta^{18} \mathrm{O}$ values suggest different interpretations, the reason for the discrepancy should be investigated. 
Measurements of $\delta^{2} \mathrm{H}$ and $\delta^{18} \mathrm{O}$ have been widely used to infer evaporative fractionation of water samples. The cryogenic extraction biases identified by Chen et al. (2020) would cause waters derived from precipitation to plot $\sim 5-11 \%$ below the meteoric water line, even in the absence of any evaporative fractionation. Thus these cryogenic extraction biases could lead researchers to infer evaporative fractionation where none has actually occurred (Fig. 2A).

Measurements of $\delta^{2} \mathrm{H}$ and $\delta^{18} \mathrm{O}$ have also been used to correct for the putative effects of evaporation, and thus to infer the isotopic composition of the original precipitation source, before any evaporative fractionation had occurred (Allen et al., 2019b; Benettin et al., 2018; Bowen et al., 2018; Evaristo et al., 2015). Here we consider how cryogenic extraction biases could affect the inferred isotopic compositions of such pre-evaporation source waters. Evaporative fractionation enriches liquid water along slopes of 2.5 to $5 \% \delta^{2} \mathrm{H}$ per $\% \delta^{18} \mathrm{O}$ (Benettin et al., 2018), and the pre-evaporation source is typically inferred from an evaporated sample by extrapolating back along this evaporation line to its intersection with the meteoric water line.

The cryogenic extraction biases described by Chen et al. (2020) imply that xylem samples may plot, on average, $\sim 8$ $\%$ farther below the meteoric water line than they otherwise would (Fig. 2B). If such a biased sample is extrapolated back along its putative evaporation line, it will intersect the meteoric water line far below the $\delta^{2} \mathrm{H}$ and $\delta^{18} \mathrm{O}$ values of its true source water (Fig. 2B). The magnitude of the resulting bias will vary depending on the slopes of the evaporation line and the meteoric water line. For evaporation slopes ranging from 2.5 to 5.0 and a meteoric water line with a slope of 8 , a cryogenic extraction bias of $-8.1 \%$ in $\delta^{2} \mathrm{H}$ will shift the inferred pre-evaporation source waters by -1.5 to $-2.7 \%$ o $\delta^{18} \mathrm{O}$ and -11.8 to $-21.6 \%$ o $\delta^{2} \mathrm{H}$, substantially amplifying the original bias in $\delta^{2} \mathrm{H}$ and introducing biases in $\delta^{18} \mathrm{O}$ (Fig. 2B).

If xylem samples are affected by cryogenic extraction biases, correctly estimating their original source waters requires first correcting for the extraction bias, before extrapolating this bias-corrected sample back along its putative evaporation line to the meteoric water line (Fig. 2C). We have applied this approach to the original data of Allen et al. (2019b) to illustrate how their estimates of evaporation-compensated (but not bias-corrected) source waters (Fig. 3A) differ from source waters that are both bias-corrected and evaporation-compensated (Fig. 3B). Using Allen et al.'s full data set and original code, we adjusted each xylem water value by $+8.1 \% \delta^{2} \mathrm{H}$ to correct for presumed cryogenic extraction biases. We then extrapolated these bias-corrected values along site-specific evaporation lines (with slopes varying from 2.9 to 3.1, depending on temperature and humidity) to intersect the local meteoric water lines (whose slopes also varied from site to site), yielding inferred preevaporation source waters that were +12.6 to $+13.1 \%$ heavier in $\delta^{2} \mathrm{H}$ than those reported by Allen et al. (compare Figs. 3A and $3 \mathrm{~B})$. If the full range of biases ( -5.2 to $\left.-10.9 \% \delta^{2} \mathrm{H}\right)$ reported by Chen et al., (2020) were applicable here, it would imply that the bias-corrected, evaporation-compensated source waters could range from +8.1 to $+17.7 \% \delta^{2} \mathrm{H}$ higher than those 215 without bias corrections.

Correcting for these presumed cryogenic extraction biases substantially weakens Allen et al.'s conclusion that there was an unexpectedly large amount of winter precipitation in mid-summer xylem water. $\mathrm{A}+8.1 \%$ shift in xylem $\delta^{2} \mathrm{H}$ increases the reported seasonal origin index values of beech, spruce, and oak from $-0.8,-0.1$, and -0.6 , respectively, to $-0.3,+0.3$, and -0.2 (where -1.0 reflects all winter precipitation and +1.0 reflects all summer precipitation in xylem water; see Allen et al., 2019b). 
220 This example demonstrates how measurement biases can propagate through post-processing steps and become substantial, even in this case where there is a large $\delta^{2} \mathrm{H}$ difference between the summer and winter precipitation end members. Conversely, however, because any such biases (and their corrections) apply similarly to all of the xylem water samples, they have minimal effects on Allen et al.'s conclusions drawn from cross-site and inter-species comparisons, such as the greater use of summer precipitation in more humid sites, or the conclusion that beech and oak use less summer precipitation than spruce does (Fig. $3)$.

\section{Further thoughts on uncertainties and error propagation}

In addition to the potential cryogenic extraction biases in xylem water $\delta^{2} \mathrm{H}$, uncertainties in quantifying the $\delta^{2} \mathrm{H}$ of end-members and mixtures should also be considered. Numerous researchers have provided code, software, and guidance regarding mathematical approaches to tracking uncertainties through mixing model analyses and using those uncertainties to assess the quality of inferences (Kirchner and Allen, 2020; Ogle et al., 2014; Phillips et al., 2014, 2005; Phillips and Gregg, 2001; Rothfuss and Javaux, 2017).

Here we illustrate how the range of -5 to $-11 \%$ o $\delta^{2} \mathrm{H}$ in cryogenic extraction biases among different tree species analyzed by Chen et al., (2020) could introduce additional uncertainty into estimates of plant water sources. We first consider a simple two-source mixing model using only the shallow and deep soils (-15 and $-28 \% \delta^{2} \mathrm{H}$, respectively) at Thorburn and Ehleringer's (1995) floodplain site as candidate end members (Fig. 1B). Thorburn and Ehleringer's reported xylem water $\delta^{2} \mathrm{H}$ from this site $(-25 \%$ ) would imply that $20 \%$ of tree water uptake was derived from the shallow soil, but this shallow water fraction would increase to $60 \%$ if a $+5 \%$ correction for cryogenic extraction were applied, and to $>100 \%$ if a $+11 \%$ correction were applied. The same mixing model applied to soil and groundwater ( -100 and $-131 \% \delta^{2} \mathrm{H}$, respectively) at Thorburn and Ehleringer's (1995) mountain-front site implies that soilwater would account for $3 \%$ of tree water uptake if the original xylem water $\delta^{2} \mathrm{H}(-130 \%$ ) were used, but $20 \%$ if a $+5 \%$ correction for cryogenic extraction were applied, and $40 \%$ if a $+11 \%$ correction were applied. These examples demonstrate that mixing model solutions are more sensitive to measurement uncertainties when differences between the end-member values are small. It should be noted that these calculations do not consider the uncertainties in the end-member values, which add to the uncertainty in the mixing model solution (and more so when the end-member $\delta^{2} \mathrm{H}$ values are closer to one another).

These uncertainties could be important even when only comparing xylem waters to other xylem waters. The cryogenic extraction biases estimated by Chen et al. (2020) vary from -5.2 to $-10.9 \% \delta^{2} \mathrm{H}$ among different species, potentially complicating any cross-species comparisons that rely on xylem $\delta^{2} \mathrm{H}$ differences of similar magnitudes. Clearly more work is needed to determine how cryogenic extraction biases vary among plant species and among individuals within species, as well as how they vary with the extraction procedures that are used (Barbeta et al., 2020b; Fischer et al., 2019; Millar et al., 2018; 


\section{Conclusion}

Our analysis shows that recently reported cryogenic extraction biases in xylem water $\delta^{2} \mathrm{H}$ are large enough to substantially affect inferences about plant water sources in many field settings. However, similar findings are likely to be only minimally affected, if they come from settings where the isotopic differences among the potential end-members are sufficiently large. Thus conclusions drawn from cryogenically extracted xylem water $\delta^{2} \mathrm{H}$ are neither generally valid nor generally invalid; what matters is the size of the potential extraction artifacts in relation to the isotopic signals in the data. Further work to quantify potential extraction artifacts will hopefully yield correction factors for a range of species and extraction protocols. These are urgently needed because evidence does not support using $8.1 \% \delta^{2} \mathrm{H}$ as a universal correction factor, although it was adopted here for illustrative purposes. In the meantime, xylem water isotope applications should be designed so that their conclusions will not be overly sensitive to known or suspected biases and uncertainties, including the potentially large uncertainties that arise from environmental heterogeneity (see, e.g., von Freyberg et al., 2020; Goldsmith et al., 2019). As demonstrated here, sensitivities to suspected biases can easily be evaluated. Thus imperfect measurements of plant and soil stable isotopes can continue to support useful inferences about plant-water relations, if study designs are appropriately matched to their likely biases and uncertainties.

Data Availability: The data used in this study are all available in previous studies. See the supplement for more precise details.

Author Contribution: STA and JWK equally contributed to the concept, analysis, and writing.

Competing interests: The authors declare that they have no conflict of interest.

Acknowledgements: This work resulted from a collaboration that has been partly funded by the Swiss Federal Office of

Environment. We thank Todd Dawson and Gregory Goldsmith for feedback on an earlier draft.

Supplementary Materials: Table S1 Details on where the reported data were sourced

\section{References}

Allen, S. T., Jasechko, S., Berghuijs, W. R., Welker, J. M., Goldsmith, G. R. and Kirchner, J. W.: 275 Global sinusoidal seasonality in precipitation isotopes, Hydrology and Earth System Sciences, 23, 3423-3436, https://doi.org/10.5194/hess-2019-61, 2019a.

Allen, S. T., Kirchner, J. W., Braun, S., Siegwolf, R. T. W. and Goldsmith, G. R.: Seasonal origins of soil water used by trees, Hydrology and Earth System Sciences, 23(2), 1199-1210, https://doi.org/10.5194/hess-23-1199-2019, 2019b.

280 Barbeta, A., Gimeno, T. E., Clavé, L., Fréjaville, B., Jones, S. P., Delvigne, C., Wingate, L. and Ogée, J.: An explanation for the isotopic offset between soil and stem water in a temperate tree species, New Phytologist, https://doi.org/10.1111/nph.16564, 2020a. 
Barbeta, A., Burlett, R., Martín-Gómez, P., Fréjaville, B., Devert, N., Wingate, L., Domec, J.-C. and Ogée, J.: Evidence for distinct isotopic composition of sap and tissue water in tree stems: consequences for plant water source identification, bioRxiv, 2020.06.18.160002, https://doi.org/10.1101/2020.06.18.160002, 2020 b.

Benettin, P., Volkmann, T. H. M., von Freyberg, J., Frentress, J., Penna, D., Dawson, T. E. and Kirchner, J. W.: Effects of climatic seasonality on the isotopic composition of evaporating soil waters, Hydrol. Earth Syst. Sci., 22(5), 2881-2890, https://doi.org/10.5194/hess-22-2881-2018, 2018.

290 Bowen, G. J., Putman, A., Brooks, J. R., Bowling, D. R., Oerter, E. J. and Good, S. P.: Inferring the source of evaporated waters using stable $\mathrm{H}$ and $\mathrm{O}$ isotopes, Oecologia, 187(4), 1025-1039, https://doi.org/10.1007/s00442-018-4192-5, 2018.

Chen, Y., Helliker, B. R., Tang, X., Li, F., Zhou, Y. and Song, X.: Stem water cryogenic extraction biases estimation in deuterium isotope composition of plant source water, PNAS, https://doi.org/10.1073/pnas.2014422117, 2020.

Dawson, T. E. and Ehleringer, J. R.: Streamside trees that do not use stream water, Nature, 350, 335337, 1991.

Ellsworth, P. Z. and Williams, D. G.: Hydrogen isotope fractionation during water uptake by woody xerophytes, Plant Soil, 291(1), 93-107, https://doi.org/10.1007/s11104-006-9177-1, 2007.

300 Evaristo, J., Jasechko, S. and McDonnell, J. J.: Global separation of plant transpiration from groundwater and streamflow, Nature, 525(7567), 91-94, https://doi.org/10.1038/nature14983, 2015.

Fischer, B. M. C., Frentress, J., Manzoni, S., Cousins, S. A. O., Hugelius, G., Greger, M., Smittenberg, R. H. and Lyon, S. W.: Mojito, Anyone? An Exploration of Low-Tech Plant Water Extraction Methods for Isotopic Analysis Using Locally-Sourced Materials, Front. Earth Sci., 7, https://doi.org/10.3389/feart.2019.00150, 2019.

von Freyberg, J., Allen, S. T., Grossiord, C. and Dawson, T. E.: Plant and root-zone water isotopes are difficult to measure, explain, and predict: Some practical recommendations for determining plant water sources, Methods in Ecology and Evolution, 11(11), 1352-1367, https://doi.org/10.1111/2041210X.13461, 2020.

310 Gaj, M. and McDonnell, J. J.: Possible soil tension controls on the isotopic equilibrium fractionation factor for evaporation from soil, Hydrological Processes, 33(11), 1629-1634, https://doi.org/10.1002/hyp.13418, 2019.

Goldsmith, G. R., Muñoz-Villers, L. E., Holwerda, F., McDonnell, J. J., Asbjornsen, H. and Dawson, T. E.: Stable isotopes reveal linkages among ecohydrological processes in a seasonally dry tropical montane cloud forest, Ecohydrology, 5(6), 779-790, https://doi.org/10.1002/eco.268, 2012. 
Goldsmith, G. R., Allen, S. T., Braun, S., Engbersen, N., González-Quijano, C. R., Kirchner, J. W. and Siegwolf, R. T. W.: Spatial variation in throughfall, soil, and plant water isotopes in a temperate forest, Ecohydrology, 12(2), e2059, https://doi.org/10.1002/eco.2059, 2019.

Kerhoulas, L. P., Kolb, T. E. and Koch, G. W.: Tree size, stand density, and the source of water used across seasons by ponderosa pine in northern Arizona, Forest Ecology and Management, 289, 425-433, https://doi.org/10.1016/j.foreco.2012.10.036, 2013.

Kirchner, J. W. and Allen, S. T.: Seasonal partitioning of precipitation between streamflow and evapotranspiration, inferred from end-member splitting analysis, Hydrology and Earth System Sciences, 24(1), 17-39, https://doi.org/10.5194/hess-24-17-2020, 2020.

$325 \mathrm{Li}, \mathrm{Y}$., Ma, Y., Song, X., Wang, L. and Han, D.: A $\delta 2 \mathrm{H}$ offset correction method for quantifying root water uptake of riparian trees, Journal of Hydrology, 593, 125811, https://doi.org/10.1016/j.jhydrol.2020.125811, 2021.

Millar, C., Pratt, D., Schneider, D. J. and McDonnell, J. J.: A comparison of extraction systems for plant water stable isotope analysis, Rapid Communications in Mass Spectrometry, 32(13), 1031-1044, https://doi.org/10.1002/rcm.8136, 2018.

Muñoz-Villers, L. E., Holwerda, F., Alvarado-Barrientos, M. S., Geissert, D. R. and Dawson, T. E.: Reduced dry season transpiration is coupled with shallow soil water use in tropical montane forest trees, Oecologia, 188(1), 303-317, https://doi.org/10.1007/s00442-018-4209-0, 2018.

Newberry, S. L., Nelson, D. B. and Kahmen, A.: Cryogenic vacuum artifacts do not affect plant wateruptake studies using stable isotope analysis, Ecohydrology, 10(8), e1892, https://doi.org/10.1002/eco.1892, 2017.

Ogle, K., Tucker, C. and Cable, J. M.: Beyond simple linear mixing models: process-based isotope partitioning of ecological processes, Ecological Applications, 24(1), 181-195, https://doi.org/10.1890/1051-0761-24.1.181, 2014.

340 Orlowski, N., Winkler, A., McDonnell, J. J. and Breuer, L.: A simple greenhouse experiment to explore the effect of cryogenic water extraction for tracing plant source water, Ecohydrology, 11(5), e1967, https://doi.org/10.1002/eco.1967, 2018a.

Orlowski, N., Breuer, L., Angeli, N., Boeckx, P., Brumbt, C., Cook, C. S., Dubbert, M., Dyckmans, J., Gallagher, B., Gralher, B., Herbstritt, B., Hervé-Fernández, P., Hissler, C., Koeniger, P., Legout, A., 345 Macdonald, C. J., Oyarzún, C., Redelstein, R., Seidler, C., Siegwolf, R., Stumpp, C., Thomsen, S., Weiler, M., Werner, C. and McDonnell, J. J.: Inter-laboratory comparison of cryogenic water extraction systems for stable isotope analysis of soil water, Hydrology and Earth System Sciences, 22(7), 36193637, https://doi.org/10.5194/hess-22-3619-2018, 2018 b. 
Phillips, D., Inger, R., Bearhop, S., Jackson, A. L., Moore, M., Parnell, A. C., Semmens, B. X. and Ward, E. J.: Best practices for use of stable isotope mixing models in food-web studies, Canadian Journal of Zoology, 92, 823-835, https://doi.org/10.1139/cjz-2014-0127, 2014.

Phillips, D. L. and Gregg, J. W.: Uncertainty in source partitioning using stable isotopes, Oecologia, 127(2), 171-179, https://doi.org/10.1007/s004420000578, 2001.

Phillips, D. L., Newsome, S. D. and Gregg, J. W.: Combining sources in stable isotope mixing models: alternative methods, Oecologia, 144(4), 520-527, https://doi.org/10.1007/s00442-004-1816-8, 2005.

Poca, M., Coomans, O., Urcelay, C., Zeballos, S. R., Bodé, S. and Boeckx, P.: Isotope fractionation during root water uptake by Acacia caven is enhanced by arbuscular mycorrhizas, Plant Soil, 441(1), 485-497, https://doi.org/10.1007/s11104-019-04139-1, 2019.

Rothfuss, Y. and Javaux, M.: Reviews and syntheses: Isotopic approaches to quantify root water uptake: a review and compar $2017,2017$.

Sprenger, M., Leistert, H., Gimbel, K. and Weiler, M.: Illuminating hydrological processes at the soilvegetation-atmosphere interface with water stable isotopes, Rev. Geophys., 54(3), 2015RG000515, https://doi.org/10.1002/2015RG000515, 2016.

365 Thorburn, P. J. and Ehleringer, J. R.: Root water uptake of field-growing plants indicated by measurements of natural-abundance deuterium, Plant Soil, 177(2), 225-233, https://doi.org/10.1007/BF00010129, 1995.

Wassenaar, L. I., Terzer-Wassmuth, S., Douence, C., Araguas-Araguas, L., Aggarwal, P. K. and Coplen, T. B.: Seeking excellence: An evaluation of 235 international laboratories conducting water 370 isotope analyses by isotope-ratio and laser-absorption spectrometry, Rapid Communications in Mass Spectrometry, 32(5), 393-406, https://doi.org/10.1002/rcm.8052, 2018.

Zuecco, G., Amin, A., Frentress, J., Engel, M., Marchina, C., Anfodillo, T., Borga, M., Carraro, V., Scandellari, F., Tagliavini, M., Zanotelli, D., Comiti, F. and Penna, D.: A comparative study of plant water extraction methods for isotopic analyses: Scholander-type pressure chamber vs. cryogenic

375 vacuum distillation, Hydrology and Earth System Sciences Discussions, 1-23, https://doi.org/10.5194/hess-2020-446, 2020. 
Consequences of increasing previously reported values of plant water $\delta^{2} \mathrm{H}$ by $8.1 \%$

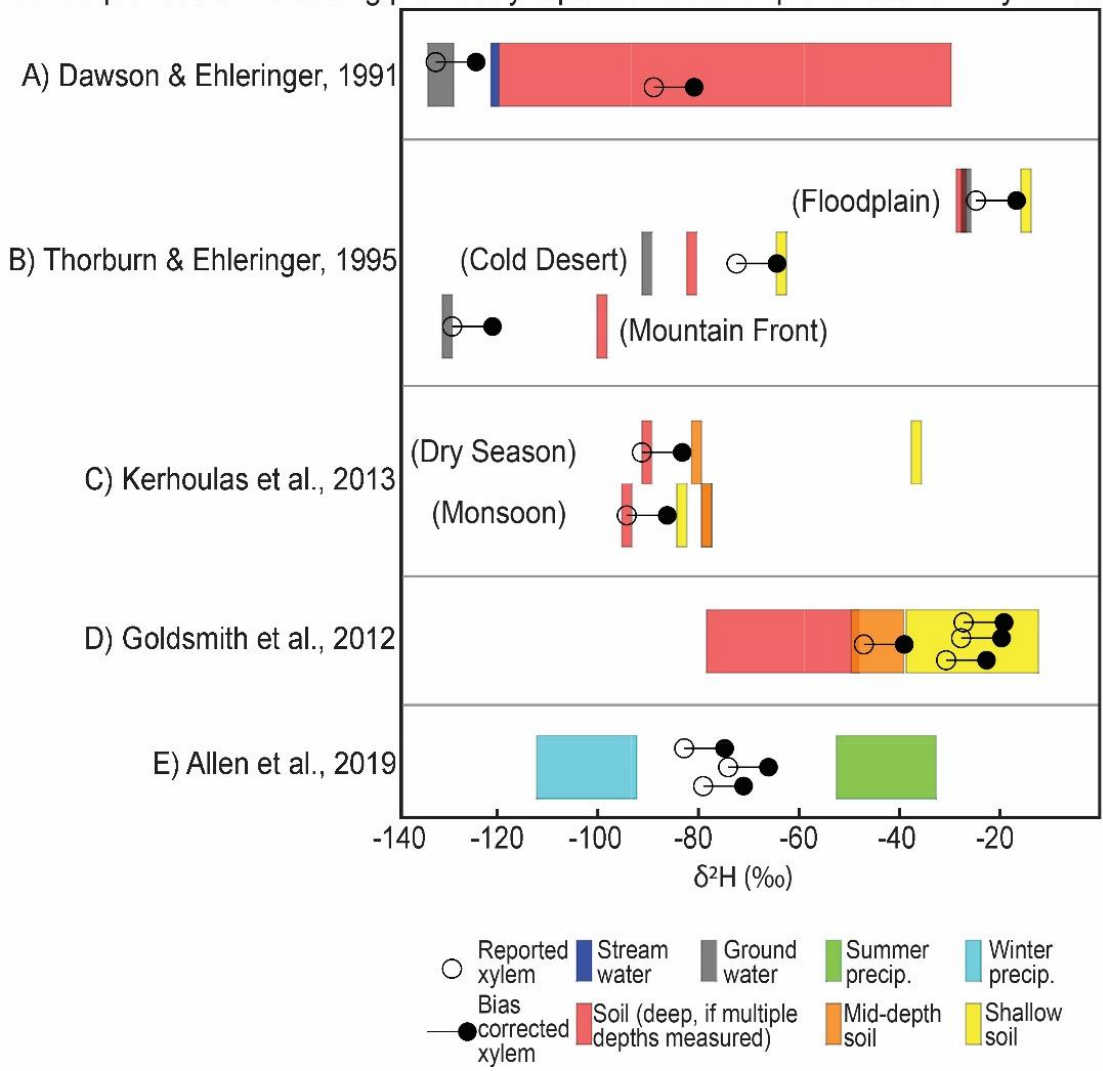

380 Figure 1 Xylem water $\boldsymbol{\delta}^{\mathbf{2}} \mathbf{H}$ values from five field studies, with and without a $+\mathbf{8 . 1} \%$ adjustment to compensate for presumed cryogenic extraction biases (open and filled circles, respectively), overlaid on $\delta^{2} \mathbf{H}$ values of potential source waters (colored bars). The meanings of the colored bar widths are study-specific, reflecting the following: \pm 1 standard deviation in stream and groundwater and the range of observations in soilwater (1A; Dawson and Ehleringer, 1991); \pm 1 \%o because uncertainties were not reported (1B; Thorburn and Ehleringer, 1995); \pm 1 standard error (1C; Kerhoulas et al., 2013); the range in soilwater values at $70-100 \mathrm{~cm}$ (deep), $50 \mathrm{~cm}$ (mid-depth), and $5-30 \mathrm{~cm}$ (shallow) (1D; Goldsmith et al., 2012); 95\% prediction intervals (1E; Allen et al., 2019b). More details about the source data are available in Table S1. A $-8.1 \%$ cryogenic extraction bias (or, conversely, a $+8.1 \%$ correction for it) will shift the relationship between the xylem water and potential source waters (and thus the inferred source attribution) more when the differences among the potential sources are smaller. 

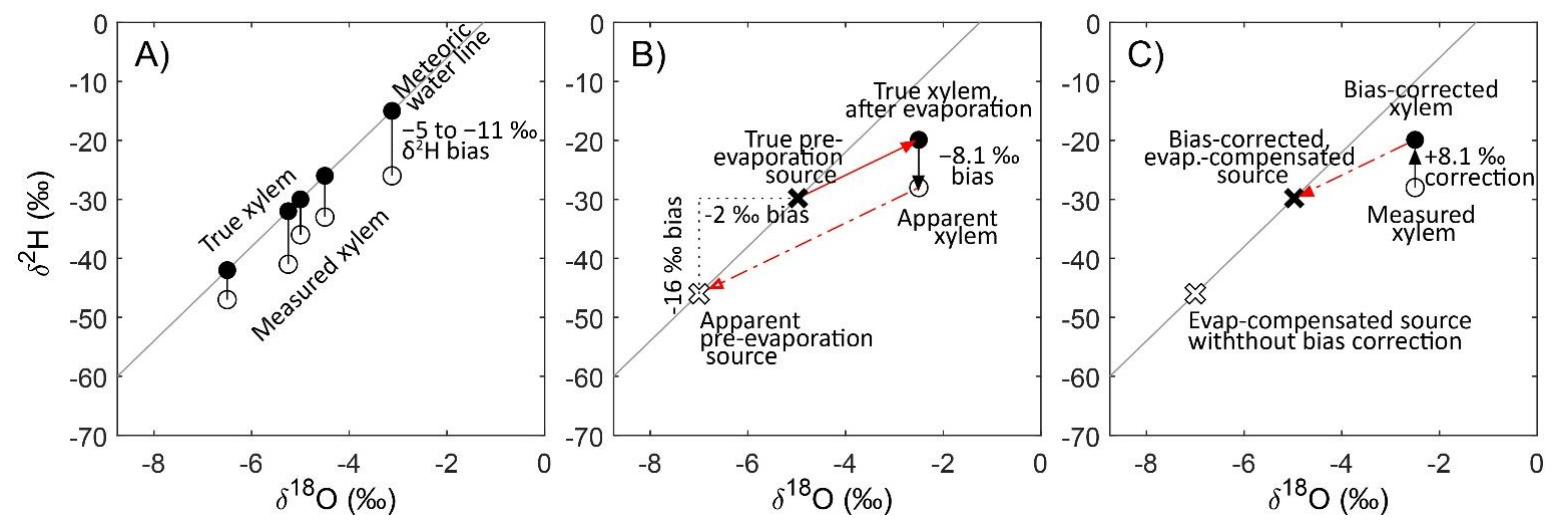

Figure 2 Implications of $\delta^{2} \mathrm{H}$ biases in dual-isotope space. A) Measurements of xylem water that would otherwise lie on the meteoric water line (implying no evaporative fractionation since that water fell as precipitation) will instead fall below the line if the water extraction process introduces a negative bias in $\delta^{2} \mathrm{H}$. This bias thus creates an apparent evaporation signal in dual-isotope space, and also artifactually suggests that the pre-evaporation source waters are lower in both $\delta^{2} \mathrm{H}$ and $\delta^{18} \mathrm{O}$ than the actual sources are. B) Biases in $\delta^{2} \mathbf{H}$ will be amplified if they are translated to inferred pre-evaporation source waters. For example, an initial precipitation source with values of $-5.0 \% \delta^{18} \mathrm{O}$ and $-30 \% \delta^{2} \mathrm{H}$ could evaporate, becoming enriched in heavy isotopes along an evaporation line with a slope of 4 (the solid red arrow), resulting in xylem water with isotope values of $-2.5 \%$ If the measured $\delta^{2} \mathrm{H}$ includes a cryogenic extraction bias of $\mathbf{- 8 . 1} \%$ (and thus is $\mathbf{- 2 8} \% \delta^{2} \mathrm{H}$ rather than the true value of $\mathbf{- 2 0} \%$ ), the apparent isotopic signature of the xylem water will suggest substantially more evaporation than actually occurred. Attempting to correct for this apparent evaporation, by extrapolating back to the meteoric water line along a slope of 4 (the dashed red arrow), will yield an apparent pre-evaporation source at $-7.0 \% \delta^{18} \mathrm{O}$ and $-46 \% \delta^{2} \mathrm{H}$. Thus the resulting bias in the apparent pre-evaporation source will be $-2 \%$ in $\delta^{18} \mathrm{O}$ and $-16 \%$ in $\delta^{2} \mathrm{H}$, relative to the true pre-evaporation source. C) If the size of the extraction bias is known, the measured xylem water can be corrected for this bias (black arrow), yielding a better estimate of the true xylem water isotope signature (black dot). Then, by evaporation-compensating the bias-corrected value (dashed red arrow), the true preevaporation source water can be inferred. 
A) Evaporation-compensated source water

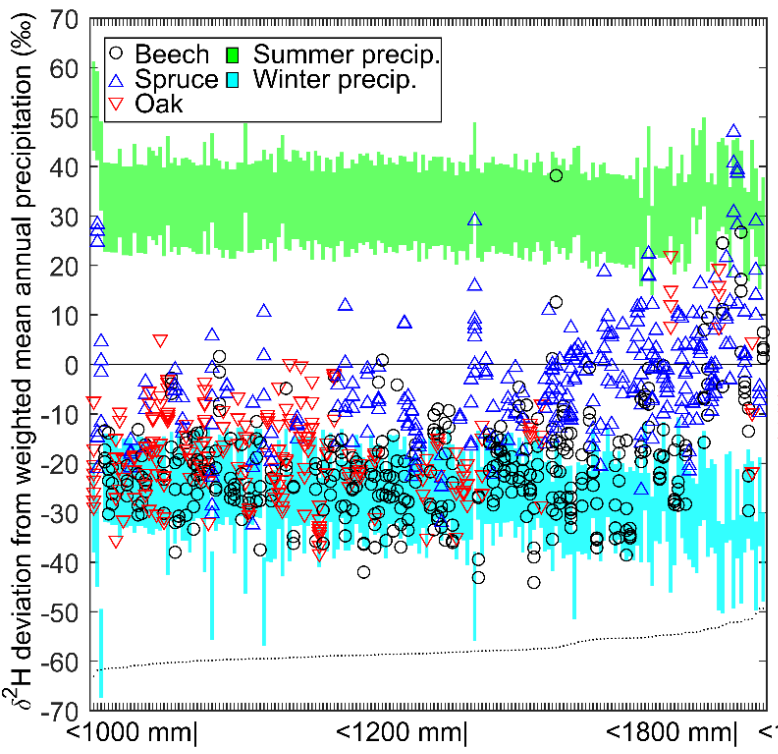

B) Bias-corrected, evaporation-compensated source water

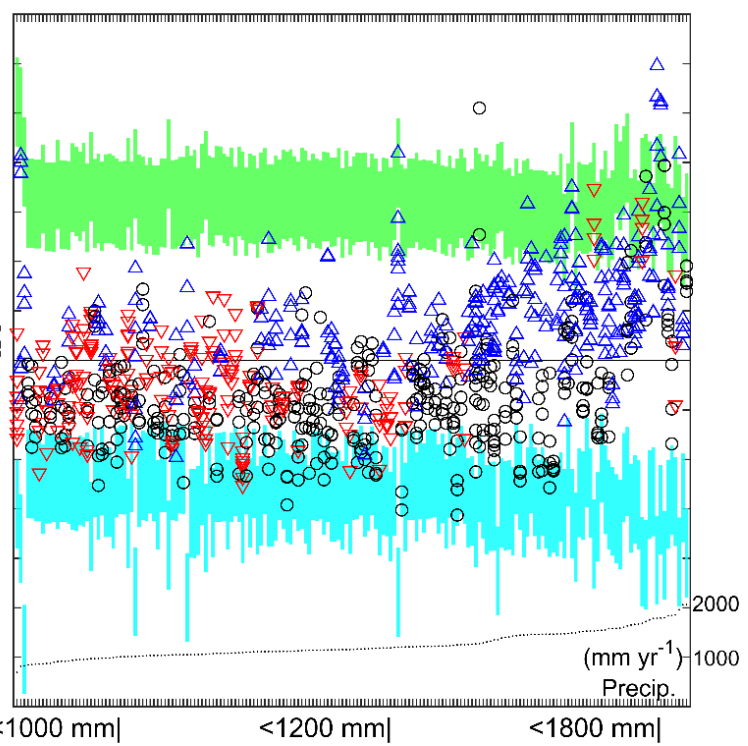

Figure 3 Evaporation-compensated xylem source water $\delta^{2} \mathbf{H}$ reported by Allen et al., 2019b (A) and the same source waters after adjusting the xylem values by $+8.1 \% \delta^{2} \mathrm{H}$ to correct for presumed cryogenic extraction bias, and after repeating Allen et al.'s evaporation-compensation calculations $(B)$. The evaporation-compensation procedure amplifies the effects of the presumed extraction bias to 12.6-13.1 \%o $\delta^{2} \mathrm{H}$, depending on the slopes of the local evaporation line and the local meteoric water line at each site (see Sect. 3). Correcting for the presumed extraction bias weakens the apparent dominance of winter precipitation at most sites. However, it has little effect on across-site trends (such as the weaker dominance of winter precipitation at wetter sites - note the trend from left to right in both panels) and on the differences among species (compare differently colored symbols in both panels). 